\title{
On transport phenomena and equilibration time scales in thermodenuders
}

\author{
R. Saleh ${ }^{1}$, A. Shihadeh ${ }^{2}$, and A. Khlystov ${ }^{1}$ \\ ${ }^{1}$ Department of Civil and Environmental Engineering, Duke University, P.O. Box 90287, Durham, NC 27708, USA \\ ${ }^{2}$ Aerosol Research Laboratory, Department of Mechanical Engineering, American University of Beirut, P.O. Box 11-0236, \\ Riad El Solh, Beirut, Lebanon
}

Received: 8 June 2010 - Published in Atmos. Meas. Tech. Discuss.: 9 July 2010

Revised: 22 February 2011 - Accepted: 11 March 2011 - Published: 18 March 2011

\begin{abstract}
This paper presents a theoretical and experimental investigation of thermodenuders that addresses two controversial issues: (1) equilibration time scales and (2) the need for an activated carbon (AC) denuder in the cooling section. We describe a plug flow model for transport phenomena in a TD, which can be used to simulate the rate of vapor build-up in the gas phase and the corresponding change in particle size distribution. Model simulations were found to have excellent agreement with experiments performed with pure and mixed dicarboxylic acid aerosols. Both simulations and experiments showed that the aerosols approached equilibrium within reasonable residence times (15s-30s) for aerosol concentrations and size distributions typical for laboratory measurements, and that volatility studies at sufficiently high aerosol loadings, therefore, need not resort to kinetic models for inference of thermodynamic properties. However, for size distributions relevant for ambient aerosols, equilibration time scales were much larger than residence times available with current TD designs. We have also performed dimensional analysis on the problem of equilibration in TDs, and derived a dimensionless equilibration parameter which can be used to determine the residence time needed for an aerosol of given size distribution and kinetic properties to approach equilibrium. It is also shown theoretically and empirically that aerosol volatility has no effect on the equilibration time scales. Model simulations and experiments showed that with aerosol size distributions relevant to both ambient and laboratory measurements re-condensation in the cooling section, with and without an AC denuder, was negligible. Thus, there is no significant benefit in using an AC denuder in
\end{abstract}

Correspondence to: A. Khlystov (andrey@duke.edu) the cooling section. Due to the risk of stripping volatile material from the aerosol, the use of AC denuders in the cooling section should be avoided. Finally, we present a rationale for why $\Delta C$ is the proper measure of volatility, while using mass fraction remaining (MFR) can be misleading.

\section{Introduction}

Ambient aerosols are complex mixtures of organics, inorganics, and water (Saxena and Hildemann, 1996; Ohta and Okita, 1990; Bardouki et al., 2003; Hueglin et al., 2005), with organic compounds comprising up to $50 \%$ of the total mass concentration (Chow et al., 1994; Murphy et al., 1998). Despite the substantial progress in the past few decades, predictions of organic aerosol (OA) concentrations by air quality models are still unable to fully reproduce ambient observations (Heald et al., 2005; Vutukuru et al., 2006). One of the main uncertainties is associated with semi-volatile OA, which constitutes a major fraction of both primary and secondary OA (Donahue et al., 2006). Semi-volatile compounds constantly re-partition between the particle and the gas phases as the temperature, relative humidity and concentrations of semi-volatile species change with time (Turpin et al., 1991; Chow et al., 1994). Thus, understanding the volatility of these organic species is of paramount importance for our ability to predict OA concentrations (Fuzzi et al., 2006; Robinson et al., 2007).

Thermodenuders have been widely used in aerosol volatility studies, both in the lab (e.g., An et al., 2007; Saleh et al., 2008; Faulhaber et al., 2009) and in the field (e.g., Wehner et al., 2002; Huffman et al., 2008; Dzepina et al., 2009). A thermodenuder (TD) is simply a temperature controlled flow

Published by Copernicus Publications on behalf of the European Geosciences Union. 
tube. When a volatile/semi-volatile aerosol is introduced into a heated TD, the particles respond by evaporating. The extent to which the particles evaporate - the difference between initial and final size distributions - provides information about their volatility. Although the operation of the TD is relatively simple, it has been the subject of some confusion. There are two main, sometimes controversial, issues associated with TDs: (1) equilibration, and (2) the need for an activated carbon denuder in the cooling section connecting the TD to the sizing instrument. The intent of including a denuder is to minimize re-condensation of the evaporated vapor back to the particles from which it originated, and thereby avoid particle size changes from the outlet of the TD to the sizing instrument.

Researchers have recently recognized the importance of kinetic limitations to volatility studies in TDs. For reliable volatility measurements, the aerosol should approach equilibrium within the residence time available in the TD, otherwise volatility would be underestimated (An et al., 2007; Saleh et al., 2008; Riipinen et al., 2010). Saleh et al. (2008, 2009, 2010) and Saleh and Khlystov (2009) found by numerical simulation and empirical measurements that the residence time in a typical TD is sufficient for equilibration at the experimental conditions of their study (aerosol concentrations higher than $200 \mu \mathrm{g} \mathrm{m}^{-3}$ and a residence time of 30 s). On the other hand, Riipinen et al. (2010) and Cappa (2010) argued, based on their evaporation kinetics models, that equilibration is not likely to be achieved for most ambient/laboratory aerosol systems within reasonable residence times. They concluded that kinetic models are necessary to interpret TD volatility measurements. It should be noted that these two studies arrived at opposite conclusions with regard to the effect of the aerosol volatility on the equilibration time scales: Riipinen et al. (2010) found that the lower volatility compounds could be equilibrated on time scales of milliseconds, if the aerosol concentration is sufficiently high, while Cappa (2010) argued that low volatility compounds cannot be equilibrated at any reasonable time scales. However, as will be shown in this paper, equilibration time is not affected by volatility.

The second controversy relates to the cooling section of thermodenuders, where the aerosol is returned to room temperature. In the cooling section, the concentration gradient is reversed, causing condensation on the aerosol particles and the walls of the cooling section. It has been feared that this re-condensation will lead to bias in the measurements, and therefore most researchers have used activated carbon (AC) denuders for cooling sections to strip the organic vapor and minimize re-condensation on the particles (e.g., An et al., 2007; Faulhaber et al., 2009; Huffman et al., 2008). It should be noted that the inclusion of an AC denuder in these studies was not justified theoretically or experimentally. Some studies (e.g., Sakurai et al., 2003; Saleh et al., 2008, 2009, 2010) found that the effect of re-condensation is negligible in their systems, and thus operated without an AC denuder. Using an aerosol evaporation kinetics model, Cappa (2010) found that bias due to re-condensation is small at low aerosol loadings, but might become substantial at high loadings.

Most of the TD studies have used aerosol particles mass fraction remaining (MFR) as an indication of aerosol volatility. MFR is defined as the ratio of aerosol particle mass concentration exiting the TD to the initial (reference) mass concentration. MFR has been used in 2 ways to infer aerosol volatility: (1) at a constant TD temperature, volatilities of different aerosol species are compared based on their MFR - the lower the MFR, the more volatile is the aerosol (e.g., An et al., 2007); (2) the TD temperature is varied until a certain MFR is reached (say 50\%), and the required TD temperatures are compared - the lower the temperature the more volatile is the aerosol (Faulhaber et al., 2009). The use of MFR to estimate volatility is theoretically unjustifiable, however, and leads to spurious results. The reason is that volatility $\left(C_{\mathrm{sat}}\right)$ of a given compound (or the average $C_{\text {sat }}$ of a mixture of compounds) does not depend on particle mass concentration, but on equilibrium between the particle phase and the gas phase, which is determined only by thermodynamic properties of the compound (or compounds and their molar fractions) in the particle phase. To illustrate, consider an aerosol with $C_{\text {sat }}(T)$ of $50 \mu \mathrm{g} \mathrm{m}^{-3}$, and two initial particle concentrations $100 \mu \mathrm{g} \mathrm{m}^{-3}$ and $500 \mu \mathrm{g} \mathrm{m}^{-3}$. If both achieve equilibrium in a TD, $\Delta C$ will be $50 \mu \mathrm{g} \mathrm{m}^{-3}$ in both cases (assuming that initial $C_{\text {sat }}$ is much smaller than $C_{\text {sat }}(T)$ ), while MFR will be 0.5 and 0.9 , respectively. Using MFR, the same aerosol would be mistakenly thought to have different volatility. The change in aerosol concentration, $\Delta C$, on the other hand is an appropriate metric for volatility studies (Saleh et al., 2008; Saleh and Khlystov, 2009).

In this paper, we present a theoretical and experimental exploration of heat and mass transport, and evaporation kinetics in thermodenuders. A plug flow computational model (Saleh and Shihadeh, 2007) is used to investigate equilibration time scales in TDs as well as potential re-condensation in the cooling section. Dimensional analysis is performed to identify the governing parameters in the equilibration problem. Theoretical findings are compared to experiments performed with pure and mixed semi-volatile dicarboxylic acid aerosols.

\section{Theory}

Consider a volatile or semi-volatile aerosol initially at equilibrium with its surrounding gas phase. The total particle mass concentration is $C_{0}$ and the vapor concentration in the gas phase is $C_{\mathrm{sat}, 0}$, the saturation concentration at the equilibrium temperature $T_{0}$. When the aerosol flows through the heating section of a TD maintained at $T_{1}>T_{0}$, a concentration gradient is created between the surface of the particles and the gas phase, and the particles respond by evaporating to bring the system to equilibrium at $T_{1}$, which corresponds 
to vapor concentration of $C_{\mathrm{sat}, 1}$ in the gas phase. If the residence time in the TD is longer than equilibration time, and provided that $C_{0}>C_{\text {sat, } 1}$, the aerosol approaches equilibrium; in other words, the gas phase approaches a saturation ratio $\mathrm{SR}=C_{\mathrm{g}} / C_{\mathrm{sat}, 1}=1$, where $C_{\mathrm{g}}$ is the vapor concentration in the gas phase. If the residence time in the TD is shorter than the equilibration time, the aerosol exits the TD with $\mathrm{SR}<1$. In the cooling section, the aerosol temperature is brought back to $T_{0}$ causing the gas phase to supersaturate with the vapor, and thereby reversing the concentration gradient. Vapor starts to condense on the particles as well as the walls of the cooling section.

The heat and mass transport phenomena in the heating and cooling sections of the TD are similar, and can be modeled using the same set of equations, but with different boundary conditions. In Sect. 2.1, we describe a plug flow model where the fluid dynamics is simplified by assuming a wellmixed flow. Dimensional analysis on the plug flow model is presented in Sect. 2.2 and is utilized to identify key parameters that govern equilibration in TDs. In Sect. 2.3, the relative importance of condensation on aerosol particles and the walls in the cooling section is investigated in terms of the coupling number previously derived by Saleh and Shihadeh (2007).

\subsection{Plug flow formulation}

In a bounded flow such as in a TD, the plug flow assumption means that there are no velocity/temperature/concentration gradients in the radial direction. This reduces the heat and mass transport problem to a set of ordinary differential equations (ODE) that can be solved as a function of axial distance or time (Saleh and Shihadeh, 2007). Furthermore, for semivolatile organics, thermal inertia of the aerosol particles and latent heat effects can be neglected (Saleh et al., 2008). Under these assumptions, the equations governing the evolution of the particulate and gas phase are as follows:

Gas phase temperature:

$$
\rho_{\mathrm{a}} c_{\mathrm{pa}} \frac{d T}{d t}=\frac{4}{d_{\mathrm{t}}} h\left(T_{\mathrm{w}}-T\right)
$$

where $\rho_{\mathrm{a}}$ is air density, $c_{\mathrm{pa}}$ is air specific heat, $d_{\mathrm{t}}$ is the TD diameter, $T_{\mathrm{w}}$ is the TD temperature, and $h$ is the average heat transfer coefficient. For laminar flow, $h$ is given by the Nusselt number correlation (Incropera and DeWitt, 2002) $N u=h d_{\mathrm{t}} / k=3.66$, where $k$ is the thermal conductivity.

\section{Gas phase vapor concentration:}

$$
\frac{d C_{\mathrm{g}}}{d t}=\frac{4}{d_{\mathrm{t}}} h_{\mathrm{m}}\left(C_{\mathrm{w}}-C_{\mathrm{g}}\right)-\sum_{i=1}^{n} \frac{d m_{\mathrm{p}, i}}{d t} N_{i}
$$

The first term on the right hand side is the mass transfer rate to the wall of the TD. $C_{\mathrm{w}}$ is the vapor concentration at the TD wall and $h_{\mathrm{m}}$ is the average mass transfer coefficient. By analogy to heat transfer, $h_{\mathrm{m}}$ can be calculated as $h_{\mathrm{m}}=h /\left(\rho_{\mathrm{a}} c_{\mathrm{pa}} L e^{2 / 3}\right)$ (Incropera and DeWitt, 2002), where $L e=D_{\mathrm{th}} / D$ is Lewis number, the ratio of thermal diffusivity to mass diffusivity. The second term on the right hand side is the net mass transfer rate to/from the ensemble of aerosol particles, which are distributed into $n$ discrete size bins, each characterized by a single diameter $d_{\mathrm{p}, i}$ and number concentration $N_{i}$. While the number concentration is held constant (i.e. no coagulation or deposition), the diameter is allowed to vary in accordance with mass transfer. The mass transfer from a single particle is given by the Maxwell equation corrected for non-continuum effects (see below).

Particle mass:

$$
\frac{d m_{\mathrm{p}, i}}{d t}=-2 \pi d_{\mathrm{p}, i} D F\left(K C_{\mathrm{sat}}-C_{\mathrm{g}}\right)
$$

where $D$ is the diffusion coefficient; $C_{\text {sat }}$ is the saturation concentration; $K=\exp \left(\frac{4 \sigma M}{\rho_{\mathrm{p}} T d_{\mathrm{p}, i}}\right)$ is Kelvin correction, where $\rho_{\mathrm{p}}$ is the particle density, $M$ is the molar mass, and $\sigma$ is the surface free energy; $F=\frac{1+K n}{1+0.3773 K n+1.33 K n(1+K n) / \alpha}$ is the Fuchs-Sutugin correction for non-continuum effects

(Fuchs and Sutugin, 1971), where $\alpha$ is the evaporation coefficient.

Equations (1)-(3) are solved using MATALB ODE23 solver, and the profiles of temperature, vapor concentration, and particle size distribution are obtained as a function of residence time in the TD. This model is used to simulate transport phenomena in both the heating section and cooling section (with and without an AC denuder) of the TD. In the heating section, a no-flux boundary condition is imposed for mass transfer at the TD wall; that is the first term in Eq. (2) is zero, when $C_{\mathrm{g}}<C_{\mathrm{sat}}\left(T_{\mathrm{w}}\right)$. If the gas phase is supersaturated due to Kelvin effect, i.e. $C_{\mathrm{g}}>C_{\mathrm{sat}}\left(T_{\mathrm{W}}\right)$, the appropriate boundary condition is $C_{\mathrm{w}}=C_{\mathrm{sat}}\left(T_{\mathrm{w}}\right)$. For the cooling section with no AC denuder, the boundary condition is set to $C_{\mathrm{w}}=C_{\mathrm{sat}}\left(T_{\mathrm{w}}\right)$, and for the cooling section with an AC denuder, the wall is assumed to be a perfect sink with $C_{\mathrm{w}}=0$.

The validity of using a plug flow model was tested by comparison with a full laminar flow model (Khlystov et al., 2009), and the difference in temperature and vapor concentration profiles for different representative cases was found to be negligible.

\subsection{The equilibration parameter $\left(t_{\mathrm{r}} / \tau\right)$}

To elucidate the parameters governing equilibration in the heating section of the TD we non-dimensionalized the above 
mass conservation and rate equations. For a monodisperse aerosol with no mass transfer to the walls, Eq. (2) simplifies to:

$\frac{d C_{\mathrm{g}}}{d t}=-\frac{d m_{\mathrm{p}}}{d t} N_{\mathrm{tot}}$

where $N_{\text {tot }}=\sum_{i=1}^{n} N_{i}$ is the total number concentration, and $m_{\mathrm{p}}$ is the mass of a single particle.

Equations (3) and (4) can be non-dimensionalized using: $t^{*}=t / t_{\mathrm{r}}$, where $t_{\mathrm{r}}$ is the residence time in the TD, $d_{\mathrm{p}}^{*}=d_{\mathrm{p}} / d_{\mathrm{p}, \text { in }}$, where $d_{\mathrm{p} \text {, in }}$ is the initial particle diameter, and $C_{\mathrm{g}}^{*}=C_{\mathrm{g}} / C_{\text {sat }}$, where $C_{\text {sat }}$ is the saturation concentration at the TD temperature. In this analysis, the time required for the thermal boundary layer to grow to fully developed conditions is assumed to be much shorter than the total residence time in the TD. This assumption is reasonable for conventional TD designs. Substituting Eq. (3) in Eq. (4) and inserting the dimensionless parameters yields:

$$
\begin{aligned}
& \frac{d C_{\mathrm{g}}^{*}}{d t^{*}}=2 \pi N_{\mathrm{tot}} d_{\mathrm{p}, \text { in }} D F t_{\mathrm{r}}\left(K-C_{\mathrm{g}}^{*}\right) d_{\mathrm{p}}^{*} \\
& \quad=\frac{t_{\mathrm{r}}}{\tau}\left(K-C_{\mathrm{g}}^{*}\right) d_{\mathrm{p}}^{*}
\end{aligned}
$$

where $\tau=1 /\left(2 \pi N_{\text {tot }} d_{\mathrm{p} \text {,in }} D F\right)$. It can be readily shown that $\tau$ physically represents the characteristic evaporation time required for an aerosol of fixed diameter and kinetic properties to produce a change in concentration in the gas phase equal to $1 / e$ of the initial difference in vapor concentration between the layer immediately surrounding the droplet phase and the gas phase, $\left(K C_{\text {sat }}-C_{\mathrm{g}}\right)$. We should note that the expression of $\tau$ is similar to the equilibration time scale previously derived by Wexler and Seinfeld (1990). $t_{\mathrm{r}} / \tau$ thus represents the ratio of time available in the TD to the characteristic time of evaporation in a bounded aerosol.

Equation (5) thus shows that the evolution of the dimensionless gas concentration $\left(C_{\mathrm{g}}^{*}\right)$ in a heated TD is characterized by a single dimensionless parameter, $t_{\mathrm{r}} / \tau$, which has no dependence on the thermodynamic properties of the aerosol, contrary to the conclusions of Riipinen et al. (2010) and Cappa (2010). It only depends on the aerosol size distribution (the total aerosol length $N_{\text {tot }} d_{\mathrm{p} \text {,in }}$ ) and kinetic properties of the aerosol, $D$ and $\alpha$ (via $F$; see Eq. 3). This result will be further illustrated in Sect. 4.3. When coupled with experimental data, $\tau$ can be used as a semi-empirical tool to predict the required residence time for a certain aerosol to achieve equilibrium, as described in Sect. 4.4.

This analysis can be readily extended to polydisperse aerosol, where the effect of the size distribution is accounted for by using the condensation sink diameter (Lehtinen et al., 2003). The condensation sink diameter is the particle diameter of a monodisperse aerosol that exhibits the same net evaporation or condensation rate as a polydisperse aerosol, both with a given number concentration. The condensation sink diameter can be calculated for a certain particle size distribution from the moment average:

$d_{\mathrm{cs}}=\left(\frac{\sum_{i+1}^{n} N_{i} d_{\mathrm{p}, i}^{a}}{\sum_{i+1}^{n} N_{i}}\right)^{1 / a}$

where the exponent $a$ varies between unity for the continuum regime and 2 for the free molecular regime. For the transition regime, it is obtained by differentiating the natural logarithm of the condensation sink $\mathrm{CS}=2 \pi D C_{\mathrm{m}} d_{\mathrm{cs}} \sum_{i+1}^{n} N_{i}$ with respect to the natural logarithm of $d_{\mathrm{p}, \mathrm{cs}}$ (Lehtinen et al., 2003):

$a=\frac{d \ln (\mathrm{CS})}{d \ln \left(d_{\mathrm{cs}}\right)}=$

$\frac{1}{\mathrm{CS}} \frac{K n+\left(0.754+\frac{8}{3 a}\right) K n^{2}+\left(0.377+\frac{16}{3 a}\right) K n^{3}+\frac{8}{3 a} K n^{4}}{\left[K n+\left(0.377+\frac{4}{3 a}\right) K n^{2}+\frac{4}{3 a} K n^{3}\right]^{2}}$

\subsection{Re-condensation in the cooling section}

In the cooling section, vapor in the gas phase condenses on both the particles and the walls of the cooling section. The process is characterized by the ratio of diffusive vapor transport to/from the particles to the convective transport to/from the cooling section walls, which can be expressed in terms of the dimensionless coupling number (Saleh and Shihadeh, 2007):

$C_{n}=2 \pi \frac{N_{\text {tot }} d_{\mathrm{p}, \text { in }} F D d_{\mathrm{t}}}{h_{\mathrm{m}}}$

$C_{n}$ represents the rate at which the vapor in the gas phase is scavenged by the droplets relative to the rate at which it is absorbed by the walls of the cooling section. The larger $C_{n}$, the greater the potential for re-condensation on the particles.

\section{Experimental}

The experimental setup used in this study (Fig. 1) is similar to the one described in Saleh et al. (2008). Aerosol is produced by spraying aqueous solutions using a constant output atomizer, and is sent to a 20 liter chamber to mix with dry, particle-free air at 40 SLPM for dilution and drying. A flow of 1 SLPM is drawn through a diffusion-dryer to remove any remaining water, while the excess is sent to exhaust. The 1 SLPM aerosol flow is then sent through a TD with a heating section of $1 \mathrm{~m}$ length and $2.5 \mathrm{~cm}$ inner diameter. The residence time in the heating section of the TD is controlled by varying the extraction flowrate using a mass flow controller. The maximum average residence time, which corresponds to a zero bypass flowrate, is around $30 \mathrm{~s}$. The default cooling section is a copper tube of $1 \mathrm{~m}$ length and $0.63 \mathrm{~cm}$ inner diameter. We have used other configurations for the cooling section, as described below. Reference and heated aerosol 


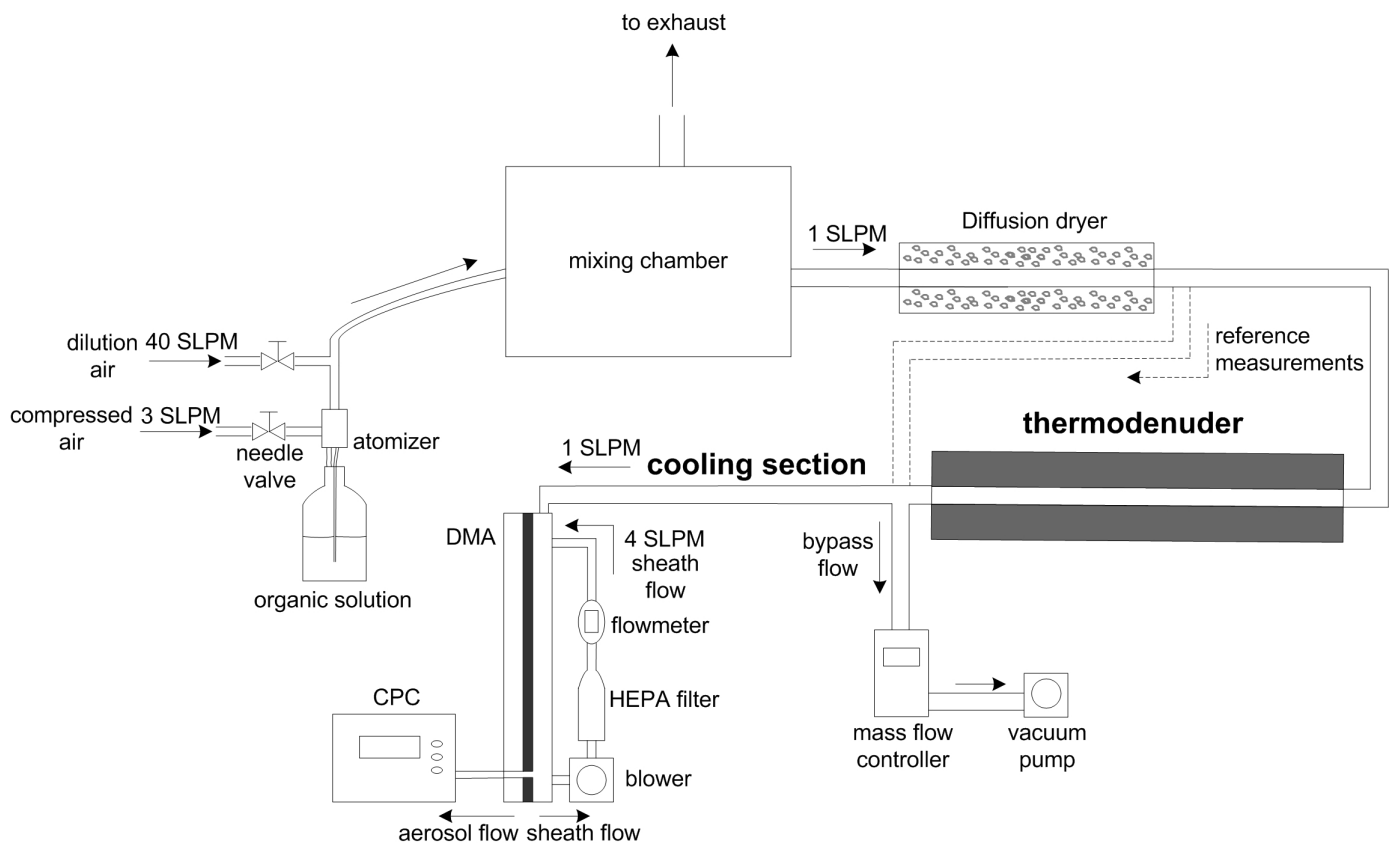

SMPS

Fig. 1. Schematic of experimental setup.

Table 1. Experimental matrix for equilibration time scales investigation.

\begin{tabular}{lccccc}
\hline Dicarboxylic acid & adipic & adipic & adipic & pimelic & mixture* \\
\hline $\begin{array}{l}\text { Mass concentration } \\
\left(\mu \mathrm{g} \mathrm{m}^{-3}\right)\end{array}$ & 390 & 245 & 68 & 307 & 313 \\
$N_{\text {tot }}\left(10^{11} \mathrm{~m}^{-3}\right)$ & 10.6 & 6.0 & 2.5 & 7.0 & 9.7 \\
$d_{\mathrm{p}, \mathrm{cs}}(\mathrm{nm})$ & 65 & 65 & 60 & 67 & 61 \\
\hline
\end{tabular}

* succinic + adipic + pimelic + azelaic mixture, with the mole fractions of the acids being respectively $0.1,0.4,0.4,0.1$.

size distributions are measured using a Scanning Mobility Particle Sizer (SMPS).

To investigate equilibration time scales, we measured the change in aerosol particle concentration $(\Delta C)$ at different residence times in the TD. Equilibration was considered achieved at a certain residence time, if $\Delta C$ did not increase with further increase in residence time. For each tested aerosol, $\Delta C$ values were measured at average residence times of $9,12,15,20$, and $30 \mathrm{~s}$.

The experimental matrix used to investigate equilibration in TDs is shown in Table 1 and the thermodynamic and kinetic properties of the test compounds are given in Table 2. The reader is advised that there are (at times significant) variations in the reported thermodynamic properties of dicarboxylic acids. However, as demonstrated in this paper, these properties do not affect the equilibration time
Table 2. Thermodynamic and kinetic properties of the dicarboxylic acids used in this study. $P_{\text {sat }, 298 \mathrm{~K}}$ and $\Delta H$ values are obtained from Saleh et al. $(2008,2009,2010)$ and $\alpha$ values are obtained from Saleh et al. (2009).

\begin{tabular}{lllll}
\hline Dicarboxylic acid & succinic & adipic & pimelic & azelaic \\
\hline$\Delta H\left(\mathrm{~kJ} \mathrm{~mol}^{-1}\right)$ & $88( \pm 3)$ & $135( \pm 13)$ & $149( \pm 10)$ & $145( \pm 15)$ \\
$P_{\text {sat }, 298 \mathrm{~K}\left(10^{-5} \mathrm{~Pa}\right)}$ & $37( \pm 11)$ & $3.4( \pm 1.2)$ & $7.2( \pm 1.7)$ & $1.4( \pm 0.5)$ \\
$C_{\text {sat }, 298 \mathrm{~K}\left(\mu \mathrm{g} \mathrm{m}^{-3}\right)}$ & $17.7( \pm 5.2)$ & $2.0( \pm 0.7)$ & $4.7( \pm 1.1)$ & $1.1( \pm 0.4)$ \\
$\alpha$ & $0.07( \pm 0.02)$ & $0.08( \pm 0.02)$ & $0.24( \pm 0.04)$ & \\
\hline
\end{tabular}

scales in thermodenuders. All experiments were performed at reference temperature of $25^{\circ} \mathrm{C}$ and TD set temperature of $40^{\circ} \mathrm{C}$. We chose adipic acid aerosol $\left(C_{0}=390 \mu \mathrm{g} \mathrm{m}^{-3}\right.$, $N_{\text {tot }}=10^{12}$ particles $\mathrm{m}^{-3}, d_{\mathrm{p}, \mathrm{cs}}=65 \mathrm{~nm}$ ) as the base case. To illustrate the dependence of equilibration time scales on aerosol loading, we varied the initial particle concentration. The effect of volatility ( $C_{\text {sat }}$ at TD temperature) was demonstrated by performing experiments with pimelic acid, which has $C_{\text {sat }}$ value a factor of 3 larger than adipic acid at $40^{\circ} \mathrm{C}$ (Saleh et al., 2008). The effect of mixture complexity was tested with a mixture of succinic, adipic, pimelic, and azelaic acids.

For the dicarboxylic acids used in this study, $C_{\text {sat }}\left(25^{\circ} \mathrm{C}\right)$ is much smaller than $C_{\mathrm{sat}}\left(40^{\circ} \mathrm{C}\right) ; C_{\mathrm{g}}^{*}$ of the organic vapor in the gas phase can thus be approximated as:

$$
C_{\mathrm{g}}^{*}=\frac{C_{\mathrm{g}}}{C_{\mathrm{sat}}\left(40^{\circ} \mathrm{C}\right)}=\frac{\Delta C+C_{\mathrm{sat}}\left(25^{\circ} \mathrm{C}\right)}{\Delta C_{\max }+C_{\mathrm{sat}}\left(25^{\circ} \mathrm{C}\right)} \approx \frac{\Delta C}{\Delta C_{\max }}
$$


Table 3. Initial (upstream of the heating section) and final (downstream of the cooling section) measured aerosol loadings for different cooling section configurations.

\begin{tabular}{lcccr}
\hline Dicarboxylic acid & adipic & adipic & mixture* & mixture* \\
\hline Initial concentration $\left(\mu \mathrm{g} \mathrm{m}^{-3}\right):^{* *}$ & 287 & 151 & 310 & 196 \\
Final concentration $\left(\mu \mathrm{g} \mathrm{m}^{-3}\right):^{* *}$ & & & & \\
$1 \mathrm{~m} \times 0.63 \mathrm{~cm}$ copper tubing, 1 LPM flowrate & 252 & 138 & 181 & 98 \\
$2 \mathrm{~m} \times 0.63 \mathrm{~cm}$ copper tubing, 1 LPM flowrate & 249 & 137 & 181 & 97 \\
$1 \mathrm{~m} \times 1.27 \mathrm{~cm}$ AC denuder, 1 LPM flowrate & 249 & 137 & 185 & 105 \\
$1 \mathrm{~m} \times 1.27 \mathrm{~cm} \mathrm{AC}$ denuder, 2 LPM flowrate & 250 & 137 & 180 & 107 \\
\hline
\end{tabular}

* succinic + adipic + pimelic + azelaic mixture, with the mole fractions of the acids being respectively $0.1,0.4,0.4,0.1$;

** the uncertainty in the measurements is approximately $\pm 5 \mu \mathrm{g} \mathrm{m}^{-3}$.

where $\Delta C_{\max }$ is the maximum change in aerosol concentration, which corresponds to equilibrium.

We have also performed experiments to examine the effect of having a cooling section with or without an AC denuder. For these experiments, the residence time in the heating section of the TD was constant at $15 \mathrm{~s}$. We measured $\Delta C$ for four cooling section configurations: (1) $1 \mathrm{~m} \times 0.63 \mathrm{~cm}$ copper tubing, which corresponds to a residence time of $2 \mathrm{~s}$; (2) $2 \mathrm{~m} \times 0.63 \mathrm{~cm}$ copper tubing, which corresponds to a residence time of $4 \mathrm{~s}$; (3) $1 \mathrm{~m} \times 1.27 \mathrm{~cm} \mathrm{AC}$ denuder, with a residence time of $8 \mathrm{~s}$; (4) $1 \mathrm{LPM}$ extraction flow was added downstream of the $\mathrm{AC}$ denuder, reducing the residence time to $4 \mathrm{~s}$. Two model aerosols were used, adipic acid, and a mixture of succinic, adipic, pimelic, and azelaic acids. The experimental matrix is given in Table 3 . The heating and the cooling section of the TD were kept at $45^{\circ} \mathrm{C}$ and $25^{\circ} \mathrm{C}$, respectively.

\section{Results and discussion}

\subsection{Effect of particle size distribution}

Figure 2 shows measured $\Delta C$ and $C_{\mathrm{g}}^{*}$ (calculated using Eq. 9) of adipic acid aerosol at different residence times in the TD for different initial particle size distributions. The results of numerical simulations using the model described in Sect. 2.1 are also shown. The equilibrium corresponds to $C_{\mathrm{g}}^{*}=1$. It is evident that equilibration times are dependent on particle size distributions - more specifically on the total particle length - as predicted by Eq. (5). For aerosol size distributions relevant for laboratory studies, adipic acid aerosol reaches equilibrium within a residence time typical for most TDs currently employed. However, for size distributions relevant for ambient measurements, equilibration requires residence times much larger than what is available with current TD designs.

It should be also noted that the asymptotic behavior, which is exhibited by $C_{\mathrm{g}}^{*}$ as the time progresses, demonstrates that the wall losses in the heated section of the thermodenuder,

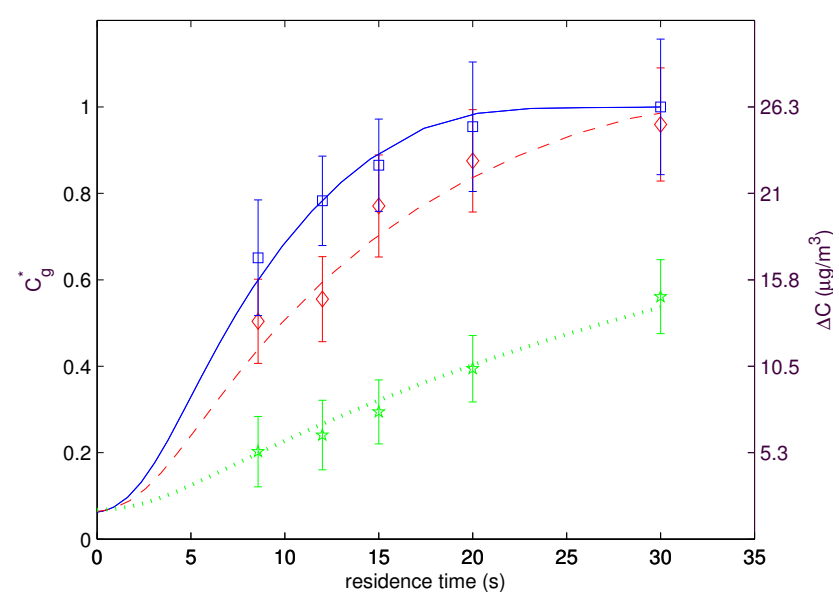

Fig. 2. Measured particle mass changes and dimensionless vapor build-up profiles for adipic acid aerosol in a TD. $T_{\text {in }}=25^{\circ} \mathrm{C}$ and $T_{\mathrm{W}}=40^{\circ} \mathrm{C}$. Blue squares and solid: $C_{0}=390 \mu \mathrm{g} \mathrm{m}^{-3}$, $N_{\text {tot }}=10^{12}$ particles $\mathrm{m}^{-3}, \quad d_{\mathrm{p}, \mathrm{cs}}=65 \mathrm{~nm} ; \quad$ red diamonds and broken: $\quad C_{0}=245 \mu \mathrm{g} \mathrm{m}^{-3}, \quad N_{\text {tot }}=6 \times 10^{11}$ particles m$^{-3}$, $d_{\mathrm{p}, \mathrm{cs}}=65 \mathrm{~nm} ; \quad$ green stars and dotted: $C_{0}=68 \mu \mathrm{g} \mathrm{m}^{-3}$, $N_{\text {tot }}=2.5 \times 10^{11}$ particles $\mathrm{m}^{-3}, d_{\mathrm{p}, \mathrm{cs}}=60 \mathrm{~nm}$. The lines show model simulations of $C_{\mathrm{g}}^{*}$ evolution.

if any, are smaller than the experimental uncertainty. If the losses were significant, there would be no such asymptotic behavior, as the material would be continuously stripped by the walls, resulting in ever increasing values of $\Delta C$. The excellent agreement between the observations and the model, which assumes no wall losses in the heated section, further supports this point.

\subsection{Effect of the evaporation coefficient}

As shown in Sect. 2.2, equilibration times depend on the evaporation coefficient $(\alpha)$ (i.e. $F$ in Eq. 5). To obtain agreement between model simulations and experimental data in Fig. 2, $\alpha$ of approximately 0.1 is required. This is consistent with the value of $\alpha$ reported by Saleh et al. (2009) for adipic 


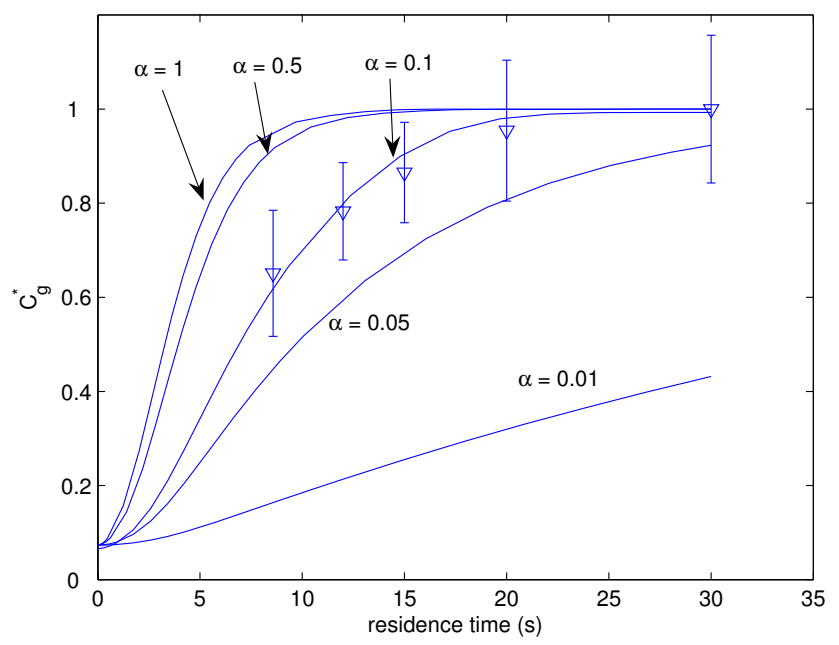

Fig. 3. Measured and simulated vapor build-up profiles for adipic acid aerosol $\left(C_{0}=390 \mathrm{\mu g} \mathrm{m}^{-3}, N_{\text {tot }}=10^{12}\right.$, particles m ${ }^{-3}$, $\left.d_{\mathrm{p}, \mathrm{cs}}=65 \mathrm{~nm}\right)$ in a TD. The simulations were performed with $\alpha$ as a variable parameter as indicated in the figure. $T_{\text {in }}=25^{\circ} \mathrm{C}$ and $T_{\mathrm{W}}=40^{\circ} \mathrm{C}$.

acid $(0.08 \pm 0.02)$. To illustrate the importance of this parameter, Fig. 3 shows model simulations for vapor build-up of adipic acid aerosol for different values of $\alpha$. It is obvious that using values of $\alpha$ greater than 0.1 over-predicts the observed $C_{\mathrm{g}}^{*}$ at short residence times, while values less than 0.1 under-predict the observations.

When TD measurements are performed at non-equilibrium conditions and the volatility is calculated from evaporation kinetics model simulations, as suggested by Riipinen et al. (2010) and Cappa (2010), the results strongly depend on $\alpha$, which is often unknown. Thus, when $\alpha$ is unknown, it is critical that TDs are used in a manner such that measurements are made under equilibrium conditions. However, as described in Sect. 4.1, equilibrium cannot be achieved in the TD when performing ambient measurements. The best approach, pending developments in the state of the art, is to interpret ambient TD measurements using kinetic models, as done in Cappa and Jimenez (2010), while keeping in mind the substantial uncertainty due to unknown $\alpha$, as pointed out by those authors.

\subsection{Effect of thermodynamic properties and mixture complexity}

To investigate the purported effect of $C_{\text {sat }}$, we performed equilibration experiments with pimelic acid, which has $C_{\text {sat }}$ $\left(40^{\circ} \mathrm{C}\right)$ a factor of 3 greater than that of adipic acid, and with a mixture of succinic, adipic, pimelic, and azelaic acids. Experimental $C_{\mathrm{g}}^{*}$ versus residence time for adipic acid, pimelic acid, and the dicarboxylic acids mixture are shown in Fig. 4 along with model predictions. Particle size distribution was held constant across the experiments, to the extent possible.

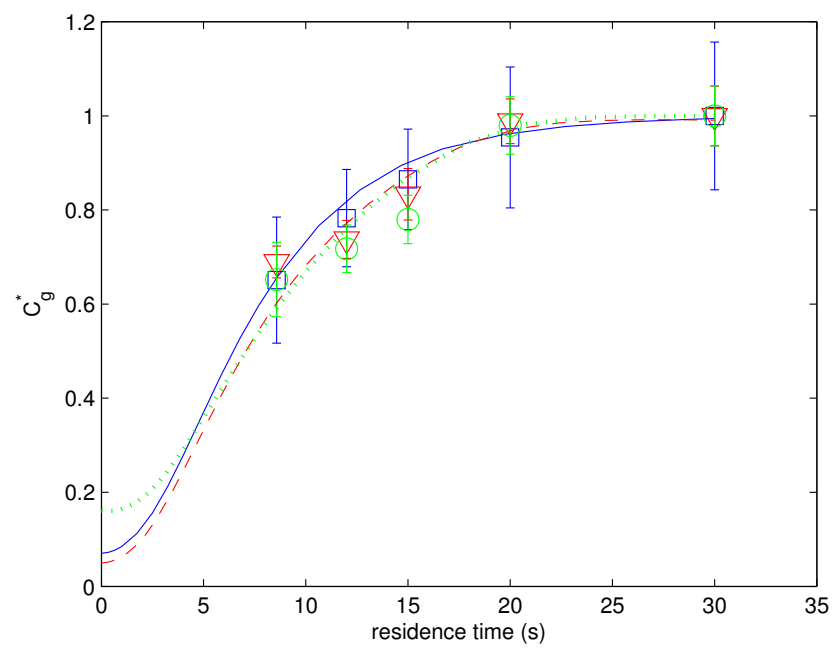

Fig. 4. Measured and simulated dimensionless vapor build-up profiles. Blue squares and solid: adipic acid, $C_{0}=390 \mu \mathrm{g} \mathrm{m}^{-3}$, $d_{\mathrm{p}, \mathrm{cs}}=65 \mathrm{~nm}$; red triangles and broken: pimelic acid, $C_{0}=307 \mu \mathrm{g} \mathrm{m}^{-3}, d_{\mathrm{p}, \mathrm{cs}}=67 \mathrm{~nm}$; green circles and dotted: succinic + adipic + pimelic + azelaic acid mixture, $C_{0}=313 \mu \mathrm{g} \mathrm{m}^{-3}$, $d_{\mathrm{p}, \mathrm{cs}}=61 \mathrm{~nm} . T_{\mathrm{in}}=25^{\circ} \mathrm{C}$ and $T_{\mathrm{W}}=40^{\circ} \mathrm{C}$.

It is apparent that the three model aerosols exhibited similar vapor build-up profiles, which verifies the theoretical finding that equilibration time scales are neither a function of $C_{\text {sat }}$ nor mixture complexity. For pimelic acid, $\alpha$ of approximately 0.25 was required for the model to match experimental data, which is in agreement with the value reported by Saleh et al. (2009) $(0.24 \pm 0.04)$. For the dicarboxylic acids mixture, the effective $\alpha$ required in the simulation was around 0.12 , which is within the range of values of the components.

It has been argued (Riipinen et al., 2010) that an aerosol with a large $C_{\text {sat }}$ needs more time to achieve equilibrium than one with a small $C_{\text {sat }}$ because the former must evaporate more than the latter to saturate the gas phase. However, this effect is counterbalanced by the increased evaporation rate of the larger $C_{\text {sat }}$ aerosol (i.e. as given by the Maxwell equation). The same applies to mixture complexity. Although in a mixture the evaporation rate of each component is reduced by a factor of $x_{i}$, the mole fraction of component $i$ in the mixture, relative to that of the pure compound, the equilibrium concentration in the gas phase of component $i$ is reduced by the same factor according to $C_{\mathrm{eq}, i}=x_{i} C_{\mathrm{sat}, i}$. This analysis can be deduced directly from the non-dimensional form of the vapor concentration rate equation (Eq. 5).

Confusion over the role of $C_{\text {sat }}$ appears to stem from how some investigators define equilibration. For example, Riipinen et al. (2010) define equilibration as the point when the aerosol particles are within $1 \%$ or $10 \mathrm{~nm}$ of the equilibrium diameter $d_{\text {eq }}$, whichever comes first. However, thermodynamic equilibrium is determined by the gas concentration, 
not particle size, i.e. the problem is mass-based. The problem with the size-based criterion can be observed by performing the following thought experiment. Consider two aerosols with the same initial size $\left(d_{0}=200 \mathrm{~nm}\right)$ and concentration $\left(C_{0}=150 \mu \mathrm{g} \mathrm{m}^{-3}\right)$, but different saturation concentrations at the TD temperature $T_{\mathrm{TD}}\left(C_{\mathrm{sat}, 1}=50 \mu \mathrm{g} \mathrm{m}^{-3}\right.$ and $C_{\text {sat,2 }}=140 \mu \mathrm{g} \mathrm{m}^{-3}$ ). Assuming that $C_{\text {sat }}$ at $T_{0}$ is much smaller than $C_{\mathrm{sat}}$ at $T_{\mathrm{TD}}$, the final equilibration concentrations are $C_{\text {eq, } 1}=C_{0}-C_{\text {sat, } 1}=100 \mu \mathrm{g} \mathrm{m}^{-3}$ and $C_{\text {eq, } 2}=C_{0}-$ $C_{\text {sat }, 2}=10 \mu \mathrm{g} \mathrm{m}^{-3}$. For spherical particles, the equilibrium diameters can be calculated from $d_{\mathrm{p}, \mathrm{eq}}=\left(\frac{6 C_{\mathrm{eq}}}{\pi \rho N}\right)^{1 / 3}$, where $\rho$ is the particle density and $N$ is the number concentration. This gives $d_{\mathrm{p}, \mathrm{eq}, 1}=175 \mathrm{~nm}$ and $d_{\mathrm{p}, \mathrm{eq}, 2}=81 \mathrm{~nm}$. Using the $1 \%$ or $10 \mathrm{~nm}$ equilibration criterion, we get $d_{\mathrm{p}, 1}=185 \mathrm{~nm}$ and $d_{\mathrm{p}, 2}=91 \mathrm{~nm}$, giving final concentrations $C_{1}$ of $118 \mu \mathrm{g} \mathrm{m}^{-3}$ and $C_{2}$ of $14 \mu \mathrm{g} \mathrm{m}^{-3}$. The saturation ratios for cases 1 and 2 can be calculated from $\mathrm{SR}_{1,2}=\frac{C_{0}-C_{1,2}}{C_{\mathrm{sat}, 1,2}}$ as $64 \%$ and $97 \%$, respectively. It is obvious that case 1 would be thought to have reached equilibrium quite prematurely relative to case 2 in an evaporation kinetics simulation, which would lead to the erroneous outcome that equilibrium at state 1 is achieved faster than state 2 , eventually leading to the invalid conclusion that equilibration time scales increase with increasing $C_{\text {sat }}$.

\subsection{The equilibration parameter $\left(t_{\mathrm{r}} / \tau\right)$}

The equilibration parameter derived in Sect. 2.2 as $t_{\mathrm{r}} / \tau=2 \pi N_{\text {tot }} d_{\text {in }} D F t_{\mathrm{r}}$ can be used semi-empirically to estimate the required residence time in a TD for a certain aerosol to equilibrate. Figure 5 shows $C_{\mathrm{g}}^{*}$ plotted as a function of $t_{\mathrm{r}} / \tau$ for the experimental data reported in Figs. 2 and 4. It can be seen in Fig. 5 that when plotted this way, the experimental data coalesce, as expected from the dimensional analysis which indicated that the process is governed by $t_{\mathrm{r}} / \tau$. The model simulations shown in Figs. 2 and 4 also collapse to approximately the same line when plotted as a function of $t_{\mathrm{r}} / \tau$, and are presented by a single solid line in Fig. 5. Using $C_{\mathrm{g}}^{*}=0.95$ as the equilibration criterion, the measured and simulated aerosols approach equilibrium for $t_{\mathrm{r}} / \tau \approx 5$. Because the derivation of $\tau$ is based on the assumption that the change in particle size upon evaporation is small, the value of $t_{\mathrm{r}} / \tau$ required for equilibration increases with deviation from the assumption. However, $\tau$ is still a valuable parameter to estimate equilibration times for most practical cases. Model simulations showed that for relative aerosol mass change $\left(\Delta C_{\text {sat }} / C_{0}\right)$ between $10 \%$ and $90 \%, t_{\mathrm{r}} / \tau$ between 5 and 9 was required for equilibration. $t_{\mathrm{r}} / \tau>9$ can thus be used to define equilibration in TDs. For an aerosol with a certain size distribution and kinetic properties, the required residence time to achieve equilibrium can thus be estimated, and the TD can be designed accordingly.

The reason why $t_{\mathrm{r}} / \tau$ required for equilibrium increases as $\Delta C_{\text {sat }} / C_{0}$ approaches unity is that when initial particle concentration, $C_{0}$, is low, the condensation sink diameter

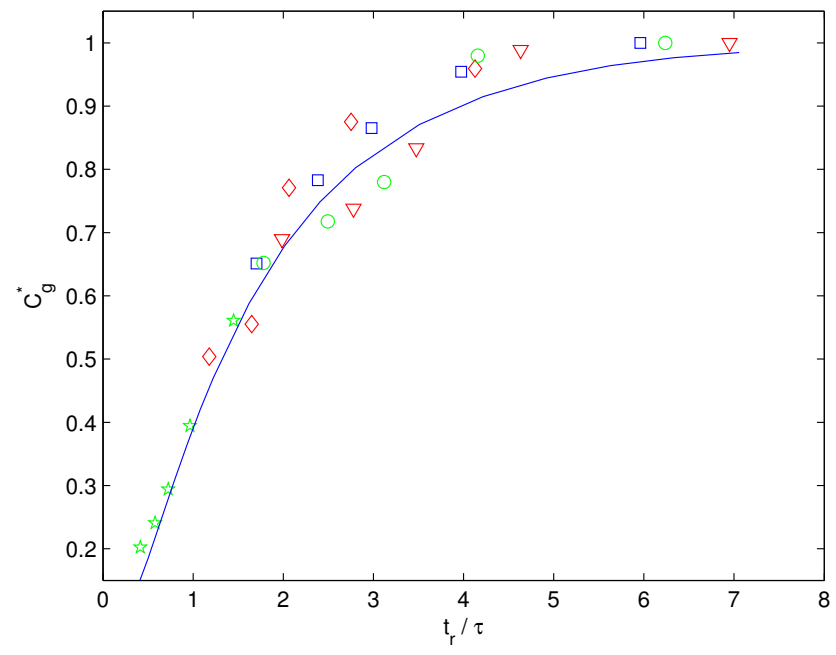

Fig. 5. Dimensionless vapor build up as a function of the equilibration parameter for the measurements in Figs. 2 and 4. The colors/symbols correspond to the same colors/symbols in Figs. 2 and 4. All the simulations in Figs. 2 and 4 collapse on the solid line. $C_{\mathrm{g}}^{*}=1$ corresponds to phase equilibrium at the TD temperature.

decreases significantly as the aerosol evaporates, causing a proportional inflation in $\tau$, and therefore a slower overall process. This can be accounted for by treating $\tau$ as a timedependent variable. The effect of $\Delta C_{\text {sat }} / C_{0}$ is illustrated in the bottom half of Fig. 6, which shows simulations for a number of model aerosols spanning a volatility range of 3 orders of magnitude. The figure shows that the equilibration process differs only for the model aerosols which are relatively lean in the particle phase (i.e. the curves corresponding to $\Delta C_{\text {sat }} / C_{0}$ of 0.5 and 0.8 ); put another way, as long as the aerosol has ample material in the particle phase relative to what is needed to saturate the vapor phase, equilibration time will be unaffected by volatility. This is more poignantly illustrated in the top half of Fig. 6, where the same data is plotted versus non-dimensional time, $t_{\mathrm{r}} / \tau(t)$, in which $\tau(t)$ is calculated using $d(t)$. It can be seen that all the curves, including those with large values of $\Delta C_{\text {sat }} / C_{0}$, collapse onto a single line, illustrating simply what is demonstrated in Eq. (5), namely that under all circumstances for which equilibration is possible $\tau$ governs the process.

When the value of $\alpha$ is unknown, which is often the case, $\tau$ can be calculated based on an assumed $\alpha$ and used to obtain a first order approximation of the required residence time. Experimental variation of TD residence time, as described in Sect. 3 , is then needed to verify that the aerosol has equilibrated. It should be noted that equilibration is possible to achieve only when $C_{0}>C_{\text {sat }}\left(T_{\mathrm{TD}}\right)-C_{\text {sat }}\left(T_{0}\right)$, otherwise the aerosol particles would evaporate completely and equilibrium will not be attained regardless of the value of $t_{\mathrm{r}} / \tau$. 


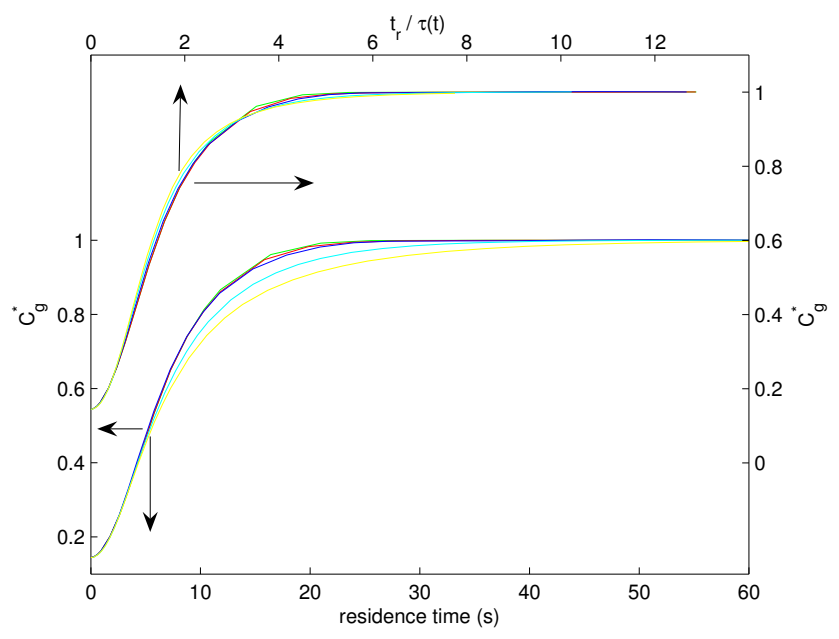

Fig. 6. Simulated normalized vapor build-up profiles in a TD as a function of residence time (bottom $\mathrm{x}$-axis and left $\mathrm{y}$-axis) and time-dependent equilibration parameter (upper $\mathrm{x}$-axis and right y-axis). $\quad T_{0}=25^{\circ} \mathrm{C} ; T_{\mathrm{TD}}=40^{\circ} \mathrm{C} ; \Delta H=100 \mathrm{~kJ} \mathrm{~mol}^{-1}$; $C_{0}=230 \mu \mathrm{g} \mathrm{m}^{-3}$; red: $C_{\mathrm{sat}}=0.14 \mu \mathrm{g} \mathrm{m}^{-3}, \Delta C_{\mathrm{sat}} / C_{0}=5 \times 10^{-4}$; green: $\quad C_{\mathrm{sat}}=1.4 \mu \mathrm{g} \mathrm{m}^{-3}, \quad \Delta C_{\mathrm{sat}} / C_{0}=5 \times 10^{-3} ; \quad$ blue: $C_{\mathrm{sat}}=14 \mu \mathrm{g} \mathrm{m}^{-3}, \quad \Delta C_{\mathrm{sat}} / C_{0}=0.05 ; \quad$ cyan: $C_{\mathrm{sat}}=140 \mu \mathrm{g} \mathrm{m}^{-3}$, $\Delta C_{\text {sat }} / C_{0}=0.5$; yellow: $C_{\text {sat }}=225 \mu \mathrm{g} \mathrm{m}^{-3}, \Delta C_{\text {sat }} / C_{0}=0.8$. Initial condensation sink diameter in all simulations is $65 \mathrm{~nm}$. $C_{\text {sat }}$ values are for $25^{\circ} \mathrm{C}$.

\subsection{Re-condensation in the cooling section}

As described in Sect. 2.3, the rate at which vapor recondenses on the aerosol particles relative to the mass transfer rate to the walls is represented by the dimensionless coupling number $C_{n}$ (Eq. 8). Figure 7 shows maximum theoretical re-condensation fraction (RF) as a function of $C_{n}$ for cooling sections with no AC denuder. RF is defined as the ratio of the amount of vapor that re-condenses on the aerosol particles when they achieve equilibrium in the cooling section to the amount of vapor that has evaporated from the particles in the TD. RF is maximum re-condensation fraction because if the aerosol is sampled from the cooling section before it achieves equilibrium there, re-condensation fraction would be less than RF. Different $C_{n}$ values were generated by randomly varying aerosol size distribution and/or cooling section geometry. As expected, re-condensation becomes more important with increasing $C_{n}$. Values of $C_{n}<0.7$ mark the region where re-condensation is not significant $(<10 \%)$. We should note that for ambient measurements and the vast majority of laboratory experiments, $C_{n}$ is well below 0.7 .

For most practical cases, incorporating an $\mathrm{AC}$ denuder has no significant effect. The reason is that value of $C_{\mathrm{g}}$ entering the cooling section is usually much greater than $C_{\mathrm{sat}}\left(T_{\mathrm{w}}\right)$, which renders the concentration gradient between the gas phase and the cooling section walls $\left(C_{\mathrm{g}}-0\right)$ with an $\mathrm{AC}$ denuder very close to the case with no AC denuder $\left(C_{\mathrm{g}}-\right.$ $\left.C_{\mathrm{sat}}\left(T_{\mathrm{w}}\right)\right)$. To illustrate, we have performed experiments with

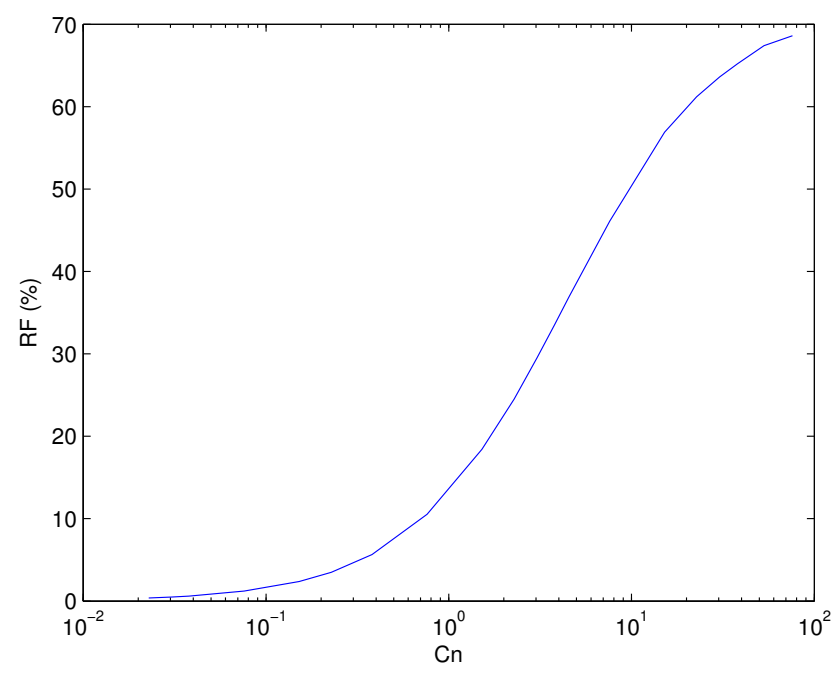

Fig. 7. Maximum re-condensation fraction as a function of $C_{n}$.

cooling sections with and without an AC denuder. The initial and final mass concentrations - downstream of the heating and cooling sections of the TD, respectively - for the cooling section configurations described in Sect. 3 are given in Table 3. As shown in the table, there was no significant difference in the final mass concentration across the four configurations for both model aerosols, which shows that the AC denuder had no observable effect in our experiments.

While harmless at short residence times, an AC denuder might become disadvantageous at long residence times, because the aerosol never achieves equilibrium. The AC denuder will continue to strip the vapor from the gas phase causing the aerosol particles to evaporate, leading to a bias in the measurement. Figure 8 shows theoretical RF for $C_{n}$ of 0.5 , for cases with and without an AC denuder. It is obvious that with an $\mathrm{AC}$ denuder the aerosol particles will continue evaporating until they completely disappear.

\subsection{TD design guidelines}

The primary design parameters for thermodenuder studies are the tube diameter, length, and flow rate. We have shown that for the heating section, equilibration is assured when $t_{\mathrm{t}} / \tau \geq 9$. Equation (5) can also be written in terms of the design parameters as:

$\frac{t_{\mathrm{r}}}{\tau}=\frac{\pi^{2}}{2} \frac{N_{\mathrm{tot}} d_{\mathrm{p}, \text { in }} D F L d_{t}^{2}}{Q}$

This formulation shows the importance of tube diameter; $t_{\mathrm{t}} / \tau$ scales with the square of the TD diameter and linearly with TD length.

Having achieved equilibrium in the heating section, the role of the cooling section is to bring the aerosol to the temperature of the sizing instrument with as little change as possible in the particle size distribution. To the extent possible, 


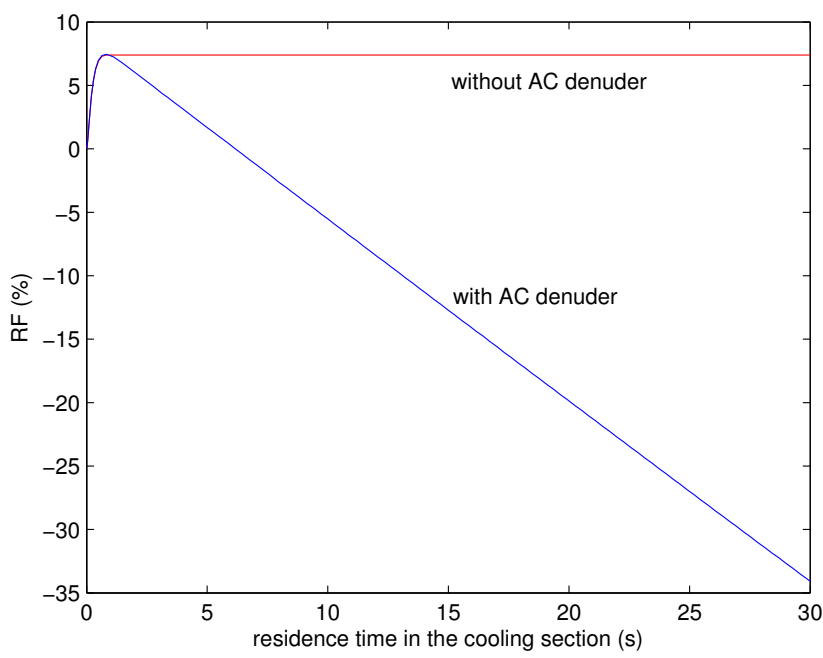

Fig. 8. Maximum re-condensation fraction as a function of residence time in the cooling section with and without an AC denuder for $C_{n}=0.5$. Negative RF indicates net evaporation of the aerosol relative to its state at the entrance of the heated TD.

condensation of the vapor phase should occur preferentially on the tube wall rather than on the particles flowing through it. For the problem at hand, cooling sections should be designed to minimize $C_{n}$. We have shown that for $C_{n}<0.7$, re-condensation is not significant. It can be readily shown that for a laminar flow characterized by a constant Sherwood number, $C_{n}$ scales with the square of the tube diameter. Thus to minimize re-condensation on the particle phase, the cooling section should have a small diameter, in contrast to the heating section.

\section{Conclusions}

Heat and mass transport and aerosol evaporation/growth kinetics in thermodenuders were studied both theoretically and experimentally. Numerical simulations of the evolution of aerosols in a TD using a plug flow computational model exhibited excellent agreement with experimental measurements performed with pure and mixed dicarboxylic acid aerosols.

For size distributions typical for laboratory experiments, we found that pure and mixed dicarboxylic acid aerosols approach equilibrium in TDs within residence times on the order of $10 \mathrm{~s}$. However, for size distributions relevant to ambient aerosols, equilibration cannot be achieved within residence times available with current TD designs.

We have shown through dimensional analysis and empirical measurements that contrary to common assumption, equilibration kinetics in a TD are not affected by volatility. Rather, equilibration time is only a function of aerosol size and number concentration, evaporation coefficient, and vapor diffusivity, as described by a time constant $\tau$. Experiments and model simulations showed that $t_{\mathrm{r}} / \tau=9$ marks the onset of equilibration, which can be used to aid TD design to ensure equilibration.

The problem of re-condensation in the cooling section can be characterized by the coupling number $\left(C_{n}\right) . C_{n}$ represents the ratio of the rate aerosol particles scavenge vapor from the gas phase to the rate vapor is transported to the walls of the cooling section. To minimize re-condensation, $C_{n}$ should be less than 0.7 , which can be achieved by minimizing the diameter of the cooling section. We showed both experimentally and by simulation that re-condensation is not important for aerosol size distributions relevant to laboratory studies and ambient measurements. We also showed that for short residence times, using an $\mathrm{AC}$ denuder in the cooling section has no effect. Further, an AC denuder might be disadvantageous, if it has a residence time long enough to distill the vapor from the gas phase which causes further evaporation of the aerosol particles. AC denuders should thus be avoided in cooling section of TDs.

Acknowledgements. The authors gratefully acknowledge funding from the NSF (grant AGS-09-55845) and the University Research Board of the American University of Beirut.

Edited by: J.-P. Putaud

\section{References}

An, W. J., Pathak, R. K., Lee, B. H., and Pandis, S. N.: Aerosol volatility measurement using an improved thermodenuder: Application to secondary organic aerosol, J. Aerosol Sci., 38, 305314, 2007.

Bardouki, H., Liakakou, H., Economou, C., Sciare, J., Smolik, J., Zdimal, V., Eleftheriadis, K., Lazaridis, M., Dye, C., and Mihalopoulos, N.: Chemical composition of size-resolved atmospheric aerosols in the eastern Mediterranean during summer and winter, Atmos. Environ., 37, 195-208, 2003.

Cappa, C. D.: A model of aerosol evaporation kinetics in a thermodenuder, Atmos. Meas. Tech., 3, 579-592, doi:10.5194/amt3-579-2010, 2010.

Cappa, C. D. and Jimenez, J. L.: Quantitative estimates of the volatility of ambient organic aerosol, Atmos. Chem. Phys., 10, 5409-5424, doi:10.5194/acp-10-5409-2010, 2010.

Chow, J., Watson, J., Fujita, E., Lu, Z., Lawson, D., and Ashbaugh, L.: Temporal and spatial variations of $\mathrm{PM}_{2.5}$ and $\mathrm{PM}_{10}$ aerosol in the Southern California Air Quality Study, Atmos. Environ., 28, 2061-2080, 1994.

Donahue, N., Robinson, A., Stanier, C., and Pandis, S.: Coupled partitioning, dilution, and chemical aging of semivolatile organics, Environ. Sci. Technol., 40, 2635-2643, 2006.

Dzepina, K., Volkamer, R. M., Madronich, S., Tulet, P., Ulbrich, I. M., Zhang, Q., Cappa, C. D., Ziemann, P. J., and Jimenez, J. L.: Evaluation of recently-proposed secondary organic aerosol models for a case study in Mexico City, Atmos. Chem. Phys., 9, 5681-5709, doi:10.5194/acp-9-5681-2009, 2009. 
Faulhaber, A. E., Thomas, B. M., Jimenez, J. L., Jayne, J. T., Worsnop, D. R., and Ziemann, P. J.: Characterization of a thermodenuder-particle beam mass spectrometer system for the study of organic aerosol volatility and composition, Atmos. Meas. Tech., 2, 15-31, doi:10.5194/amt-2-15-2009, 2009.

Fuchs, N. and Sutugin, A.: High dispersed aerosols, in: Topics in Current Aerosol Research, vol. 2, Pergamon Press, Oxford, 1971.

Fuzzi, S., Andreae, M. O., Huebert, B. J., Kulmala, M., Bond, T. C., Boy, M., Doherty, S. J., Guenther, A., Kanakidou, M., Kawamura, K., Kerminen, V.-M., Lohmann, U., Russell, L. M., and Pöschl, U.: Critical assessment of the current state of scientific knowledge, terminology, and research needs concerning the role of organic aerosols in the atmosphere, climate, and global change, Atmos. Chem. Phys., 6, 2017-2038, doi:10.5194/acp-62017-2006, 2006.

Heald, C. L., Jacob, D. J., Park, R. J., Russell, L. M., Huebert, B. J., Seinfeld, J. H., Liao, H., and Weber, R. J.: A large organic aerosol source in the free troposphere missing from current models, Geophys. Res. Lett., 32, L18809, doi:10.1029/2005GL023831, 2005.

Hueglin, C., Gehrig, R., Baltensperger, U., Gysel, M., Monn, C., and Vonmont, H.: Chemical characterization of $\mathrm{PM}_{2.5}, \mathrm{PM}_{10}$, and coarse particles at urban, near-city and rural sites in Switzerland, Atmos. Environ., 39, 637-651, 2005.

Huffman, J., Ziemann, P., Jayne, J., Worsnop, D., and Jimenez, J.: Development of fast stepping/scanning thermodenuder for chemically-resolved aerosol volatility measurements, Aerosol Sci. Tech., 42, 395-407, 2008.

Incropera, F. and DeWitt, D.: Fundamentals of heat and mass transfer, John Wiley \& Sons Inc, New York, 2002.

Khlystov, A., Lin, M., Bolch, M., and Ma, Y.: Positive artifact formation during sampling semi-volatile aerosol using wet denuders, Atmos. Environ., 43, 364-370, 2009.

Lehtinen, K., Korhonen, H., Dal Maso, M., and Kulmala, M.: On the concept of condensation sink diameter, Boreal Environ. Res., 8, 405-411, 2003.

Murphy, D., Thomson, D., and Mahoney, M.: In situ measurements of organics, meteoritic material, mercury, and other elements in aerosols at 5 to 19 kilometers, Science, 282, 1664-1669, 1998.

Ohta, S. and Okita, T.: A chemical characterization of atmospheric aerosol in Sapporo, Atmos. Environ., 24, 815-822, 1990.

Riipinen, I., Pierce, J., Donahue, N., and Pandis, S.: Equilibration time scales of organic aerosol inside thermodenuders: Evaporation kinetics versus thermodynamics, Atmos. Environ., 44, 597$607,2010$.
Robinson, A., Donahue, N., Shrivastava, M., Weitkamp, E., Sage, A., Grieshop, A., Lane, T., Pierce, J., and Pandis, S.: Rethinking organic aerosols: Semivolatile emissions and photochemical aging, Science, 315, 1259-1262, 2007.

Sakurai, H., Park, K., McMurry, P., Zarling, D., Kittelson, D., and Ziemann, P.: Size-dependent mixing characteristics of volatile and nonvolatile components in diesel exhaust aerosols, Environ. Sci. Technol., 37, 5487-5495, 2003.

Saleh, R. and Khlystov, A.: Determination of activity coefficients of binary semi-volatile organic aerosols using the Integrated Volume Method, Aerosol Sci. Tech., 43, 838-846, 2009.

Saleh, R. and Shihadeh, A.: Hygroscopic growth and evaporation of an aerosol with boundary heat and mass transfer, J. Aerosol Sci., 38, 1-16, 2007.

Saleh, R., Walker, J., and Khlystov, A.: Determination of saturation pressure and enthalpy of vaporization of semi-volatile aerosols: The integrated volume method, J. Aerosol Sci., 39, 876-887, 2008.

Saleh, R., Shihadeh, A., and Khlystov, A.: Determination of evaporation coefficients of semi-volatile organic aerosols using an Integrated Volume - Tandem Differential Mobility Analysis (IVTDMA) method., J. Aerosol Sci., 40, 1019-1029, 2009.

Saleh, R., Khlystov, A., and Shihadeh, A.: Effect of aerosol generation method on measured thermodynamic properties of dicarboxylic acid aerosols, Aerosol Sci. Tech., 44, 302-307, 2010.

Saxena, P. and Hildemann, L.: Water-soluble organics in atmospheric particles: A critical review of the literature and application of thermodynamics to identify candidate compounds, J. Atmos. Chem., 24, 57-109, 1996.

Turpin, B., Huntzicker, J., Larson, S., and Cass, G.: Los-Angeles summer midday particulate carbon - primary and secondary aerosol, Environ. Sci. Technol., 25, 1788-1793, 1991.

Vutukuru, S., Griffin, R., and Dabdub, D.: Simulation and analysis of secondary organic aerosol dynamics in the South Coast Air Basin of California, J. Geophys. Res.-Atmos., 111, D10S12.1D10S12.13, 2006.

Wehner, B., Philippin, S., and Wiedensohler, A.: Design and calibration of a thermodenuder with an improved heating unit to measure the size-dependent volatile fraction of aerosol particles, J. Aerosol Sci., 33, 1087-1093, 2002.

Wexler, A. and Seinfeld, J.: The distribution of ammonium salts among a size and composition dispersed aerosol, Atmos. Environ., 24, 1231-1246, 1990. 